\title{
VALORES E MOTIVAÇÕES PARA RESPONDER SEM PRECONCEITO FRENTE A HOMOSSEXUAIS ${ }^{1}$
}

\author{
Valdiney Veloso Gouveia* \\ Rebecca Alves Aguiar Athayde \\ Ana Karla Silva Soares \\ Rafaella de Carvalho Rodrigues Araújo \\ Josemberg Moura de Andrade
}

\begin{abstract}
RESUMO. Neste artigo se objetivou conhecer os correlatos valorativos das motivações interna e externa para encarar sem preconceito a homossexualidade. Foram realizados dois estudos. No Estudo 1 participaram 234 pessoas de João Pessoa, com idade média de 26 anos, que responderam à Escala de Motivações para Responder sem Precocietos Frente a Gays e ao Questionário dos Valores Básicos e perguntas demográficas. A motivação interna se correlacionou com as subfunções suprapessoal (+) e normativa (-), enquanto a motivação externa o fez com existência (+) e normativa (+). O Estudo 2 reuniu 202 pessoas da mesma população, com idade média de 25 anos. Elas responderam os mesmos instrumentos, tendo as lésbicas como grupo-alvo. As motivações interna e externa se correlacionaram com a subfunção normativa (- e +, respectivamente). Concluindo, os valores predisseram adequadamente as motivações para olhar sem preconceito a homossexualidade e os achados foram discutidos a partir do modelo dual de valores.
\end{abstract}

Palavras-chave: Valores; preconceito; homossexual.

\section{VALUES AND MOTIVATION TO RESPOND WITHOUT PREJUDICE TOWARD HOMOSSEXUALS}

\begin{abstract}
This paper aimed to know the value correlates of the internal and external motivations to respond without prejudice against homosexuals. Two studies were performed. In Study 1 participated 234 people from Joao Pessoa, with an average age of 26 years. They answered the Motivations to Respond without Prejudice toward Gays Scale, the Basic Value Survey, and demographic questions. The internal motivation was correlated with suprapersonal (+) and normative (-) subfunctions, meanwhile the external motivation was correlated with existence (+) and normative (+) ones. The Study 2 involved 202 people from the same population, with an average age of 25 years. They answered the same instruments, although considering lesbians as target-group. The internal and external motivations were correlated with the subfunction normative (- and + , respectively). In conclusion, the values adequately predicted the motivations to respond without prejudice toward homosexuals, being these findings discussed based on the dual model of values.
\end{abstract}

Key words: Values; prejudice; homosexual.

\section{VALORES Y MOTIVACIÓN PARA RESPONDER SIN PREJUICIO HACIA HOMOSEXUALES}

RESUMEN. Se objetivó conocer los correlatos valorativos de las motivaciones interna y externa para responder sin prejuicio hacia los homosexuales. Dos estudios fueron realizados. El Estudio 1 reunió 234 personas de João Pessoa (edad promedia de 26 años), que contestaron a la Escala de Motivaciones para Responder sim Prejuicio hacia los Gays, el Cestionario de los Valores Básicos y preguntas demográficas. La motivación interna se correlacionó con las subfunciones suprapersonal (+) y normativa (-), a la vez que la externa lo hizo con existencia (+) y normativa (+). El Estudio 2 contó con 202 personas de esta población (edad promedia de 25 años). Ellos contestaron los mismos instrumentos, siendo las

1 Apoio: CNPq; Universidade Federal da Paraíba.

Doutor em Psicologia Social (1998) pela Universidade Complutense de Madri. Professor Titular na Universidade Federal da Paraíba e Pesquisador 1A do CNPq.

\# Mestanda em Psicologia Social na Universidade Federal da Paraíba.

II Doutor em Psicologia pela Universidade de Brasília, Professor Adjunto do Departamento de Psicologia da Universidade Federal Paraíba. 
lésbicas el grupo-blanco. Las motivaciones interna y externa se correlacionaron con la subfunción normativa (- y + , respectivamente). Concluyendo, los valores predijeron las motivaciones para responder sin prejuicio hacia los homosexuales, siendo estos hallazgos discutidos según el modelo dual de los valores.

Palabras-clave: Valores; prejuicio; homosexual.

Em seu livro "The nature of prejudice" Allport (1954) afirma que o preconceito é uma atitude hostil e desfavorável, relacionada a um julgamento errôneo, inalterável e generalizado. Tal construto envolve ainda uma aversão sentida ou expressada que pode ser direcionada a um grupo ou a um de seus membros. Pesquisas recentes buscam explicar as mudanças ocorridas no tocante ao preconceito e afirmam que este fenômeno ainda está longe de findar-se (Formiga, Vasconcelos, Joca, \& Saraiva, 2005; Lima \& Vala, 2004), adquirindo apenas uma forma nova de manifestação (Pettigrew \& Meertens, 1995).

Entre os grupos minoritários que sofrem com o preconceito podem-se citar os homossexuais - gays e lésbicas - que são vítimas de discriminação e injustiças desde épocas remotas (Formiga, Omar, \& Vaamonde, 2009; Toro-Alfonso \& Varaz-Díaz, 2004). Na civilização greco-romana as relações homoeróticas, principalmente as masculinas, eram repudiadas apenas quando se apresentavam como uma ameaça à hierarquia social da época; porém a tradição judaicocristã trouxe uma perspectiva mais depreciativa em relação aos homossexuais, atribuindo-lhes uma conotação pecaminosa (Lacerda, Pereira, \& Camino, 2002).

Na sociedade contemporânea a sexualidade vem sendo considerada como uma dimensão definidora do sujeito e essencial à formação de sua identidade pessoal. Isto, porém, não significa que este processo seja harmonioso; ao contrário, ser de um sexo e assumir atributos, comportamentos e afetos reservados ao outro sexo ainda gera desconforto na sociedade, passando os indivíduos correspondentes a ser vistos como desviantes e pervertidos (Costa, 2007; Ramos \& Carrara, 2006; Torrão Filho, 2005). Apesar desta constatação, percebe-se nos dias de hoje um padrão de conduta socialmente desejável, que desaprova atitudes preconceituosas. Não obedecer a este padrão pode implicar em reprovação social por parte dos demais, inclusive submeter o sujeito a punições legais (Plant \& Devine, 1998).

Diante destas constatações, diversas pesquisas vêm procurando entender o que motiva as pessoas a se desproverem de preconceito, discutindo se estas motivações são reflexos de mudanças nas atitudes pessoais ou decorrem meramente de pressões sociais (Gouveia, Souza Filho, Araújo, Guerra, \& Sousa,
2006; Plant \& Devine, 1998). Plant e Devine (1998), as principais autoras na área, defendem a existência de motivações tanto internas quanto externas para proceder sem preconceito quanto à homossexualidade. A propósito, procurando compreender os efeitos das motivações para proceder sem preconceito, elas desenvolveram uma medida específica a respeito, denominada Escala de Motivação Interna e Externa para Responder sem Preconceito. A motivação interna representa características pessoais não preconceituosas que foram internalizadas, enquanto a motivação externa resulta de uma pressão social para seguir normas não preconceituosas, evidenciando uma preocupação com a aprovação social dos demais.

Os resultados de diversas pesquisas sobre $o$ preconceito (Gouveia et al., 2006; Pereira, Torres, Pereira, \& Falcão, 2011) mostraram não haver dúvidas de que as pessoas tendem a evitar demonstrá-lo em relação a grupos minoritários (e.g., negros, gays, lésbicas, ciganos). Tal tendência parece estar ligada tanto a disposições de personalidade - como a desejabilidade social (Rattazzi \& Chiara, 2003) -, quanto a elementos de socialização, como os princípios axiológicos que orientam a vida das pessoas (Gouveia et al., 2006). O presente estudo considera precisamente os correlatos valorativos das motivações para proceder sem preconceito em relação a gays e lésbicas. Neste sentido, faz-se necessária uma exposição breve acerca da relação entre valores humanos e preconceito.

\section{PRECONCEITO E VALORES}

As atitudes negativas em relação aos homossexuais vêm sendo estudadas a partir de diversas perspectivas, representando uma tentativa dos pesquisadores de conhecer como o preconceito se desenvolve e se manifesta, o que permite pensar em ações afirmativas ou, pelo menos, atenuantes, que promovam intervenções com vista à sua redução (Toro-Alfonso \& Varaz-Díaz, 2004). De acordo com Gómez e Huici (2001), os estudos a respeito se dividem em três enfoques principais: (1) teorias do novo racismo; (2) ênfase na congruência de crenças ao tratar das relações intergrupais; e (3) ênfase na diferença da hierarquia de valores dos que compõem 
os exogrupos, pela qual se pode conhecer como o indivíduo se relaciona com o mundo físico e social (Tamayo, Lima, Marques, \& Martins, 2001).

Em estudo realizado por Whitley e Egisdóttir (2000) observou-se que as atitudes em relação a homossexuais são influenciadas por crenças e opiniões estabelecidas culturalmente. De forma específica, seus resultados apontaram que o preconceito sexual pode ser explicado, por exemplo, pelo desejo dos heterossexuais de manter as tradições com relação ao gênero, as quais estariam sendo transgredidas pelos homossexuais.

Utilizando a tipologia de Pettigrew e Meertens (1995), Lacerda et al. (2002) realizaram uma pesquisa com estudantes universitários sobre a natureza da homossexualidade. Estes autores observaram que os preconceituosos flagrantes explicam a homossexualidade a partir de princípios éticos, morais e religiosos; os preconceituosos sutis explicam-na pelos aspectos biológicos e psicológicos; e os não preconceituosos explicam-na por aspectos psicossociais.

Vera e Martínez (1994) realizaram um estudo com estudantes universitários com a utilização dos tipos motivacionais de S. H. Schwartz (1994), buscando conhecer em que medida os valores deste modelo explicam o nível de preconceito em relação a grupos minoritários. Neste caso, observaram que as pessoas com nível menos elevado de preconceito dão maior importância ao tipo motivacional universalismo, enquanto o tipo tradição é mais pontuado entre aqueles com maior nível de preconceito.

Vasconcelos, Gouveia, Souza Filho, Sousa e Jesus (2004) fizeram uma pesquisa para conhecer em que medida os valores humanos estão relacionados com as atitudes preconceituosas e a intenção de manter contato social com pessoas negras. Seus resultados foram consistentes com achados anteriores. Por exemplo, por meio de uma análise de regressão múltipla estes mesmos autores constataram que os valores suprapessoais e de realização predisseram satisfatoriamente as atitudes preconceituosas, sobretudo no que diz respeito à intenção de não manter contato social com negros. As atitudes relativas aos ciganos também foram explicadas por valores suprapessoais no contexto espanhol (Martínez, Paterna, \& Gouveia, 2006), reforçando sua pertinência. Concretamente, as pessoas que dão importância a tais valores costumam ser menos preconceituosas.

Como parece evidente, a maioria dos estudos preocupa-se em observar indicadores diretos de atitudes ou crenças preconceituosas (Gómez \& Huici,
2001; Vera \& Martinéz, 1994); não obstante, é igualmente importante considerar as motivações que levam as pessoas a evitar demonstrar preconceito contra grupos minoritários, conhecendo suas bases valorativas. Com esse propósito, Gouveia et al. (2006) procuraram conhecer em que medida os valores humanos se correlacionam com a motivação para proceder sem preconceito em relação a pessoas negras. Seus participantes foram estudantes universitários e pessoas da população geral, aos quais foram aplicados dois instrumentos: a Escala de Motivação Interna e Externa para Responder sem Preconceito (Plant \& Devine, 1998) e o Questionário dos Valores Básicos (Gouveia, Milfont, Fischer, \& Santos, 2008). Os resultados indicaram que as motivações internas se correlacionaram mais fortemente com valores suprapessoais (por exemplo, beleza, maturidade), enquanto as externas o fizeram com os de realização (por exemplo, prestígio, privacidade).

Em síntese, os resultados demonstram que as atitudes preconceituosas podem ser inibidas ou são menos evidentes entre pessoas cujos princípios transcendem contextos específicos, como os baseados em valores universalistas (Gómez \& Huici, 2001; Vera \& Martinéz, 1994) ou suprapessoais (Martínez et al., 2006). No caso das motivações para proceder sem preconceito, especialmente quanto à motivação interna, que expressa uma resposta intrinsecamente não preconceituosa, tais valores são igualmente preponderantes; mas a maioria dos estudos a respeito tem tido como foco os negros. Então é de se perguntar: tais motivações apresentam as mesmas bases axiológicas quando são tidos em conta os gays e as lésbicas? Esta pergunta principal orientou o presente artigo, justificando-se em razão da escassez de evidências empíricas a respeito da importância de conhecer os correlatos valorativos do preconceito, o que leva a pensar em programas de educação em valores como forma de minimizar condutas consequentes de discriminação de gays e lésbicas.

Antes de apresentar os estudos realizados procurar-se-á resumir a abordagem assumida sobre os valores humanos.

\section{TEORIA FUNCIONALISTA DOS VALORES HUMANOS}

Esta teoria vem sendo elaborada nos últimos anos (Gouveia et al., 2008), procurando integrar diferentes modelos anteriores acerca dos valores humanos (por 
exemplo, Inglehart, 1991; Schwartz, 1994); entretanto é claramente mais parcimoniosa, permitindo, por exemplo, explicar porcentagens de variância iguais ou superiores àquelas proporcionadas pelo modelo de $\mathrm{S}$. H. Schwartz (Boer, 2009; Guerra, 2008; Lauer-Leite, 2009). Sua parcimônia advém do fato de propor unicamente duas dimensões a partir das quais derivar os valores, as quais são combinadas para derivar seis subfunções valorativas, que claramente abarcam os dez tipos motivacionais de S. H. Schwartz (Gouveia, 2003). Procurar-se-á, a seguir, detalhar algo mais este modelo.

Ao elaborarem seu modelo, Gouveia et al. (2008) assumem três pressupostos teóricos: (1) admitem a natureza benevolente do ser humano; (2) pensam que os valores são representações cognitivas das necessidades individuais, demandas da sociedade e institucionais, que restringem os impulsos pessoais e asseguram um ambiente estável e seguro; e (3) consideram como apropriado tratá-los como terminais, expressando um propósito em si, sendo definidos como substantivos. Seu modelo considera as funções dos valores, as quais são escassamente tratadas na literatura.

Quanto aos pressupostos previamente descritos, Gouveia et al. (2008) identificaram duas funções principais dos valores: eles guiam as ações do homem (tipo de orientação; Rokeach, 1973; Schwartz, 1994) e expressam suas necessidades (tipo de motivador; Inglehart, 1991). Rokeach (1973) divide os valores terminais em sociais, que compreendem os de caráter interpessoal, e pessoais, considerados de foco intrapessoal. Por sua vez, Gouveia et al. (2008) identificaram alguns valores que figuram entre os pessoais e os sociais, pois são congruentes com ambos, recebendo a denominação de valores centrais. Estes valores representam o eixo motivador ao longo do tipo de orientação.

Apesar de reconhecerem que não há uma correspondência perfeita entre necessidades e valores, Gouveia et al. (2008) pensam que é possível definir os valores como expressões das necessidades humanas. Neste sentido, sugerem que todos os valores sejam classificados como materialistas (pragmáticos) ou idealistas (abstratos), o que está de acordo com o que tem sido proposto na literatura (Inglehart, 1991). Os valores materialistas compreendem ideias práticas, implicando uma orientação para metas específicas e regras normativas. Os valores idealistas demonstram uma orientação universal, baseada em ideias e princípios mais abstratos. Tais valores são coerentes com um espírito inovador, sugerindo menos dependência de bens materiais. Isto é, as ações não se limitariam ao contexto social imediato ou concreto; as pessoas orientadas por tais valores teriam uma visão mais ampla do mundo.

Semelhantemente ao que foi anteriormente comentado, Gouveia et al. (2008) definiram duas dimensões funcionais dos valores: tipo de orientação (social, central e pessoal) e tipo de motivador (materialistas e idealistas). Cruzando-se estas dimensões é possível identificar seis subfunções valorativas (quadrantes entre parênteses): a normativa (social-materialista), a interativa (social-idealista), existência (central-materialista), suprapessoal (central-idealista), realização (pessoal-materialista) e experimentação (pessoal-idealista). Cada uma destas subfunções é descrita como segue, listando-se os valores específicos correspondentes:

- Existência: representa valores compatíveis com as orientações sociais e pessoais, situando-se no domínio motivador materialista; significa que são asseguradas as condições básicas de sobrevivência biológica e psicológica. Estes valores são referência para aqueles que representam as subfunções realização e normativa, sendo existência o motivador materialista principal. Três de seus valores são estabilidade pessoal, saúde e sobrevivência.

- Realização: são compreendidos como valores desta subfunção aqueles que expressam o motivador materialista, com orientação pessoal. As pessoas orientadas por tais valores têm como foco realizações materiais e buscam a praticidade em decisões e comportamentos. São exemplos típicos os valores êxito, poder e prestígio.

- Normativa: descreve uma orientação social, tendo como foco regras sociais e um princípio-guia materialista; este reflete a importância de preservar a cultura e as normas sociais. Seus valores são a vida social, a estabilidade grupal e o respeito por símbolos e padrões culturais que prevaleceram durante anos. Ela pode ser representada pelos valores específicos obediência, religiosidade e tradição.

- Suprapessoal: abarca valores com orientação central e motivador idealista. Pensa-se que os seres humanos têm uma necessidade biológica de informação (curiosidade) que os conduz à compreensão e domínio do mundo físico e social. Esta tendência é expressa por essa subfunção, que é referência para a interativa e a experimentação. Suprapessoal é a subfunção principal do motivador idealista, sendo representada pelos valores beleza, conhecimento e maturidade. 
- Experimentação: representa o motivador idealista, porém com uma orientação pessoal. Os valores que a integram favorecem a promoção de mudança e inovação na estrutura das organizações sociais, principalmente a partir da busca de situações novas, permitindo experimentar realidades desafiantes. Três valores que podem descrevê-la são emoção, prazer e sexualidade.

- Interativa: os valores que representam esta subfunção permitem retratar as necessidades de pertença, amor e afiliação, promovendo o estabelecimento e a manutenção de relações interpessoais por parte do indivíduo. Esta subfunção representa o motivador idealista com orientação social, expressando valores como afetividade, apoio social e convivência.

Este modelo teórico vem reunindo evidências empíricas de sua adequação em diversos estudos realizados no contexto nacional (Santos, 2008) e internacional (Boer, 2009; Guerra, 2008), porém ainda são escassas as pesquisas que o têm empregado para compreender o preconceito (Martínez et al., 2006; Vasconcelos et al., 2004), sobretudo as motivações para responder sem preconceito (Gouveia et al., 2006). Especificamente, nenhuma pesquisa foi encontrada em que se empregasse este ou outro modelo dos valores para explicar as motivações para olhar sem preconceito os homossexuais. Como anteriormente indicado, este pode ser um aspecto relevante, principalmente por serem os valores uma variável contingencial, possibilitando intervenção no sentido de modificar atitudes e comportamentos indevidos (Rokeach, 1973).

A seguir são apresentados os estudos que avaliam a correlação entre esses construtos.

\section{ESTUDO 1. VALORES E MOTIVAÇÕES PARA PROCEDER SEM PRECONCEITO EM RELAÇÃO AOS GAYS}

Este estudo buscou conhecer os correlatos valorativos das motivações para portar-se sem preconceito com gays, bem como avaliar o poder preditivo dos valores para explicar os fatores de motivações externas e internas.

\section{Método}

\section{Amostra}

Participaram do estudo 234 pessoas da população geral de João Pessoa (PB), com idades entre 15 e 63 anos $(m=26,0, d p=10,43)$, a maioria do sexo feminino $(54,3 \%)$ e heterossexual (95\%). Esta foi uma amostra de conveniência (não probabilística) e se constituiu de indivíduos que, tendo sido convidados, decidiram participar voluntariamente.

\section{Instrumentos}

Os participantes responderam a três instrumentos: Questionários de Valores Básicos; Escala de Motivações Interna e Externa para Responder sem Preconceito; e informações demográficas e indicadores de preconceito.

- O Questionário dos Valores Básicos foi elaborado com base no modelo teórico proposto por Gouveia et al. (2008), e se compõe de dezoito itens ou valores específicos, entre eles, conhecimento (procurar notícias atualizadas sobre assuntos pouco conhecidos; tentar descobrir coisas novas sobre o mundo) e poder (ter poder para influenciar os outros e controlar decisões; ser o chefe de uma equipe). $\mathrm{O}$ indivíduo deve ler cada valor e avaliar em que medida o considera importante como um princípio que guia sua vida, respondendo de acordo com uma escala de sete pontos, variando de $1=$ Totalmente não importante a $7=$ Extremamente importante.

- A Escala de Motivações Interna e Externa para Responder sem Preconceito foi elaborada por Plante e Devine (1998) e se constitui de dez itens distribuídos igualmente em dois fatores de motivação: interna (por exemplo, "Procuro agir de forma não preconceituosa em relação aos gays porque isso é importante para mim”); e externa (por exemplo, "Se eu agir de forma preconceituosa contra gays vou me preocupar se as pessoas vão ficar com raiva de mim”). Estes itens avaliam em que medida as pessoas dão respostas não preconceituosas em relação a exogrupos, neste caso, os homossexuais. Os itens devem ser respondidos em escala de nove pontos, variando de $1=$ Discordo totalmente a $9=$ Concordo totalmente. Emprega-se nesta oportunidade a versão brasileira desta medida, formada por oito itens, igualmente distribuídos nos dois fatores de motivação (Gouveia et al., 2006).

- Informações demográficas e indicadores de preconceito: com a finalidade de caracterizar os participantes do estudo, incluíram-se perguntas demográficas (idade, sexo, preferência sexual, religiosidade e número de amigos íntimos), além de questões para avaliar o contato dos participantes com gays. Neste caso, indagou-se acerca de quantos de seus amigos íntimos eram 
homossexuais, se conheciam alguém que tem preconceito em relação aos homossexuais e se alguém da família tem preconceito com relação à preferência sexual.

\section{Procedimento}

Os participantes responderam em locais públicos (por exemplo, shoppings, parques), porém o fizeram individualmente, auxiliados, quando necessário, por aplicadores devidamente treinados. Todos os instrumentos eram, em princípio, autoaplicáveis, indicando-se que não haveria respostas certas ou erradas e enfatizando-se a necessidade de os participantes serem sinceros em suas respostas, expressando como de fato pensam, sentem e/ou agem no seu dia a dia. Informou-se que a pesquisa teria caráter confidencial e que os dados seriam tratados estatisticamente em conjunto. Todos os preceitos éticos foram respeitados e os participantes (ou seus responsáveis) foram solicitados a assinar o Termo de Consentimento Livre e Esclarecido. Em média, cada um demorou 20 minutos para concluir sua participação no estudo.

\section{Análise de dados}

Para a tabulação e análise dos dados foi utilizado o SPSS (versão 15). Foram calculadas, inicialmente, estatísticas descritivas, com o intuito de apurar as medidas de tendência central e de dispersão. Posteriormente foram calculadas as correlações das subfunções valorativas e valores específicos com os tipos de motivação, além de serem realizadas análises de regressão múltipla (stepwise) para estimar o poder preditivo dos valores específicos para explicar as motivações de responder sem preconceito.

\section{Resultados}

Inicialmente, procurou-se correlacionar todas as subfunções e os valores específicos com os dois tipos de motivação para portar-se sem preconceito em relação a gays, conforme mostram as primeiras colunas da tabela 1. Procura-se a seguir descrever as correlações segundo o tipo de motivação.

Tabela 1. Correlatos Valorativos das Motivações para Responder Sem Preconceito

\begin{tabular}{|c|c|c|c|c|}
\hline \multirow{3}{*}{ Subfunções e valores } & \multirow{2}{*}{\multicolumn{2}{|c|}{$\begin{array}{c}\text { Gays } \\
\text { Tipos de Motivação }\end{array}$}} & \multicolumn{2}{|c|}{ Lésbicas } \\
\hline & & & \multicolumn{2}{|c|}{ Tipos de Motivação } \\
\hline & Interna & Externa & Interna & Externa \\
\hline Experimentação & $\mathbf{0 , 0 3}$ & 0,03 & 0,04 & $-\mathbf{0 , 0 1}$ \\
\hline Prazer & 0,02 & 0,01 & 0,02 & 0,02 \\
\hline Emoção & 0,04 & $-0,01$ & 0,07 & $-0,02$ \\
\hline Sexual & $-0,02$ & 0,05 & 0,01 & 0,03 \\
\hline Realizaçãa & $\mathbf{0 , 0 7}$ & 0,02 & $\mathbf{- 0 , 0 9}$ & 0,06 \\
\hline Exito & $0,14^{*}$ & $-0,10$ & $-0,03$ & $-0,04$ \\
\hline Prestígio & 0,07 & $0,15^{*}$ & 0,04 & $0,15^{*}$ \\
\hline Poder & $-0,11 *$ & $-0,02$ & $-0,16^{*}$ & $-0,02$ \\
\hline Existência & $-0,08$ & $0,11 *$ & $-0,03$ & $0,15^{*}$ \\
\hline Saúde & $-0,01$ & 0,10 & $-0,03$ & 0,11 \\
\hline Estabilidade Pessoal & $-0,14^{*}$ & 0,06 & $-0,07$ & $0,18 * *$ \\
\hline Sobrevivência & $-0,01$ & 0,08 & 0,05 & 0,01 \\
\hline Suprapessoal & $0,19 * *$ & $-0,10 *$ & $\mathbf{0 , 1 1}$ & $-0,06$ \\
\hline Maturidade & $0,12^{*}$ & $-0,04$ & 0,07 & $-0,05$ \\
\hline Beleza & $0,20 * *$ & $-0,09$ & 0,11 & $-0,08$ \\
\hline Conhecimento & $0,10^{*}$ & $-0,03$ & $-0,01$ & 0,06 \\
\hline Interativa & 0,08 & $-0,01$ & $\mathbf{- 0 , 0 1}$ & 0,01 \\
\hline Afetividade & 0,01 & $-0,06$ & $0,18 * *$ & $-0,02$ \\
\hline Convivência & 0,05 & 0,05 & $-0,06$ & 0,01 \\
\hline Apoio Social & 0,09 & $-0,01$ & 0,03 & $0,15^{*}$ \\
\hline Normativo & $\mathbf{- 0 , 1 3} *$ & 0,01 & $-0,12 *$ & $0,16 *$ \\
\hline Tradição & $-0,02$ & 0,03 & 0,03 & $0,16^{*}$ \\
\hline Religiosidade & $-0,16^{* *}$ & 0,02 & $-0,18^{* *}$ & $0,14^{*}$ \\
\hline Obediência & $-0,09$ & 0,07 & $-0,14 *$ & 0,02 \\
\hline
\end{tabular}

Notas. $* p<0,05 ; * * p<0,01$ (teste unicaudal)

Motivação Interna: duas subfunções valorativas se correlacionaram com este tipo de motivação para conduzir-se sem preconceito em relação a gays: as subfunções suprapessoal $(r=0,19, p<0,01) \mathrm{e}$ 
normativa ( $r=-0,13, p<0,05)$. Em termos dos valores específicos, os seguintes apresentaram correlações significativas: beleza ( $r=0,20, p<0,01)$, religiosidade $(r=-0,16, p<0,01)$, êxito $(r=0,14, p<0,05)$, estabilidade pessoal $(r=-0,14, p<0,05)$, maturidade $(r=0,12, p<0,05)$, poder $(r=-0,11, p<0,05) \mathrm{e}$ conhecimento $(r=0,10, p<0,05)$.

Motivação Externa: duas subfunções valorativas se correlacionaram com este tipo de motivação para conduzir-se sem preconceito em relação a gays: as funções existência $(r=0,11, p<0,05)$ e suprapessoal $(r=-0,10, p<0,05)$. Um único valor específico se mostrou relevante neste contexto: prestígio $(r=0,15$, $p<0,05)$.

Para conhecer o poder preditivo dos valores humanos como explicadores dos tipos de motivação para conduzir-se sem preconceito, foram efetuadas duas análises de regressão múltipla. No caso, para evitar o efeito de multicolinearidade, estabeleceu-se o método de regressão stepwise. Considerou-se em cada análise o tipo de motivação como variável-critério e os valores específicos como variáveis antecedentes (preditoras). Os resultados estão resumidos na tabela 2.

Tabela 2. Regressão Linear (stepwise) das Motivações Interna e Externa para Responder Sem Preconceito Frente a Gays (Valores Humanos Como Preditores)

\begin{tabular}{|c|c|c|c|c|c|c|c|}
\hline & Preditores & $\mathbf{R}$ & $\mathbf{R}_{\text {ajustado }}^{2}$ & $\mathbf{F}$ & B & Beta & $\mathbf{t}$ \\
\hline \multirow{3}{*}{ 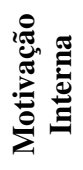 } & Beleza & 0,19 & 0,03 & $\mathrm{~F}(195)=9,00 * *$ & 0,79 & 0,19 & $3,00 * *$ \\
\hline & :Exito & 0,24 & 0,04 & $\mathrm{~F}(194)=4,48^{*}$ & 0,91 & 0,13 & $2,11 *$ \\
\hline & Estabilidade pessoal & 0,27 & 0,06 & $\mathrm{~F}(193)=4,29^{*}$ & $-0,73$ & $-0,13$ & $-2,07 *$ \\
\hline 苞 & Prestígio & 0,16 & 0,02 & $F(194)=6,41^{* *}$ & 0,51 & 0,16 & $2,53^{*}$ \\
\hline
\end{tabular}

Notas. * $p<0,05, * * p<0,01$.

Quanto à motivação interna, os seguintes valores foram os mais importantes preditores: beleza $(\beta=$ $0,19, p<0,01)$, êxito $(\beta=0,13, \mathrm{p}<0,05)$ e estabilidade pessoal $(\beta=-0,13, p<0,05)$, os quais explicaram conjuntamente $6 \%$ da variância total ( $\mathrm{R}^{2}$ ajustado). No caso da motivação externa, unicamente o valor prestígio foi incluído como preditor $(\beta=0,16$, $\mathrm{p}<0,05)$, explicando $2 \%$ da variância total $\left(\mathrm{R}^{2}\right.$ ajustado).

Em resumo, parece evidente que a subfunção suprapessoal é a mais importante para explicar a motivação interna para proceder sem preconceito, com destaque para o valor beleza. Este resultado parece consistente com o que tem sido observado na literatura (Gómez \&Huici, 2001; Martínez et al., 2006; Vera \& Martínez, 1994). A motivação externa é escassamente explicada pelos valores em relação aos gays. Neste ponto cabe o seguinte questionamento: são estes valores os mesmos quando se tem em conta outro grupo-alvo, como as lésbicas? Para responder a esta pergunta, realizouse o estudo que se descreve a seguir.

\section{ESTUDO 2. VALORES E MOTIVAÇÕES PARA PROCEDER SEM PRECONCEITO EM RELAÇÃO A LÉSBICAS.}

Este estudo procurou replicar o anteriormente descrito, conhecendo os correlatos valorativos das motivações para proceder sem preconceito em relação aos homossexuais, especificamente às lésbicas. $\mathrm{O}$ propósito último foi conhecer o poder preditivo dos valores para explicar as motivações externa e interna para proceder sem preconceito em relação a pessoas deste grupo.

\section{Método}

\section{Amostra}

Participaram 202 pessoas da população geral de João Pessoa (PB). A amostra foi escolhida de conveniência (não probabilística), sendo incluídas no estudo as pessoas que, convidadas, decidiram colaborar voluntariamente. As idades dos participantes variaram entre 15 e 71 anos $(m=24,9, d p=9,62)$, sendo a maioria do sexo feminino $(60,9 \%)$ e heterossexual $(95 \%)$. 


\section{Instrumentos, procedimento e análise de dados}

Os participantes responderam aos mesmos instrumentos descritos no Estudo 1 (Escala de Motivação Externa e Interna para proceder sem Preconceito e Questionário dos Valores Básicos e Caracterização Demográfica); contudo, os itens da escala de motivações para proceder sem preconceito foram descritos diferentemente de acordo com o grupo minoritário tratado, isto é, a palavra gays foi substituída por lésbica - por exemplo: "É importante para meu autoconceito não ser preconceituoso com lésbicas; procuro não apresentar preconceito contra lésbicas, para evitar a desaprovação dos outros). As instruções sobre como responder aos instrumentos e sobre o procedimento de aplicação e a análise de dados foram descritas no estudo anterior.

\section{Resultados}

Como no Estudo 1, procurou-se primeiramente apresentar as correlações de todas as subfunções e seus valores com as motivações para proceder sem preconceito, agora em relação a lésbicas. Os resultados correspondentes são listados nas duas últimas colunas da tabela 1 .
A seguir são resumidas as correlações por tipo de motivação:

- Motivação interna: uma única subfunção valorativa se correlacionou com este tipo de motivação: a normativa ( $r=-0,12, p<0,05)$. Os valores específicos foram mais numerosos, compreendendo: afetividade $(r=0,18, p<0,01)$, religiosidade $(r=-0,18, p<0,01)$, poder $(r=-0,16$, $p<0,05)$ e obediência $(r=-0,14, p<0,05)$.

- Motivação externa: duas subfunções valorativas se correlacionaram com este tipo de motivação: existência $(r=0,15, p<0,05)$ e normativa $(r=$ $0,16, p<0,05)$, e quatro foram os valores específicos que se relacionaram: estabilidade pessoal $(r=0,18, p<0,01)$, tradição $(r=0,16, p<$ $0,05)$, prestígio $(r=0,15, p<0,05)$ e religiosidade $(r=0,14, p<0,05)$.

Foram feitas duas análises de regressão múltipla (método stepwise), considerando-se em cada uma o tipo de motivação como variável critério e os valores específicos como variáveis antecedentes (preditoras). Os resultados são mostrados na tabela 3 a seguir.

Tabela 3 - Regressão Linear (Stepwise) das Motivações Interna e Externa para Responder sem Preconceito Frente a Lésbicas (Valores Humanos Como Preditores)

\begin{tabular}{|c|c|c|c|c|c|c|c|}
\hline & Preditores & $\mathbf{R}$ & $\mathbf{R}_{\text {ajustado }}^{2}$ & $\mathbf{F}$ & B & Beta & $\mathbf{t}$ \\
\hline \multirow{3}{*}{ 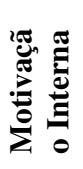 } & Afetividade & 0,18 & 0,03 & $\mathrm{~F}(195)=6,71 * *$ & 0,36 & 0,18 & $2,59 * *$ \\
\hline & 'Religiosidade & 0,29 & 0,08 & $\mathrm{~F}(194)=8,83^{* *}$ & $-0,23$ & $-0,23$ & $-3,26^{* *}$ \\
\hline & Poder & 0,34 & 0,11 & $\mathrm{~F}(193)=8,38^{* *}$ & $-0,16$ & $-0,18$ & $-2,64 * *$ \\
\hline \multirow{2}{*}{ 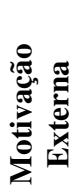 } & Estabilidade Pessoal & 0,19 & 0,04 & $\mathrm{~F}(194)=7,95^{* *}$ & 0,31 & 0,19 & $2,82 * *$ \\
\hline & Tradição & 0,24 & 0,06 & $\mathrm{~F}(193)=6,01^{* *}$ & 0,13 & 0,14 & $1,98 * *$ \\
\hline
\end{tabular}

Notas. $* p<0,05, * * p<0,01$.

Quando a motivação interna foi considerada como variável critério, três valores específicos emergiram como seus preditores ( $p<0,01$ para todos): afetividade $(\beta=0,18)$, religiosidade $(\beta=-0,23) \mathrm{e}$ estabilidade pessoal $(\beta=-0,18)$, os quais explicaram conjuntamente $11 \%$ da variância total ( $\mathrm{R}^{2}$ ajustado). Quanto à motivação externa, dois foram seus preditores ( $p<0,01$ para ambos): estabilidade pessoal $(\beta=0,19)$ e tradição $(\beta=0,14)$, explicando conjuntamente $6 \%$ da variância total $\left(\mathrm{R}^{2}\right.$ ajustado).

Em resumo, os resultados do presente estudo vão na direção do anteriormente descrito. Ao que parece, o elemento mais diferenciador foi a inclusão de mais valores para explicar as motivações externas para proceder sem preconceito em relação às lésbicas, sobretudo daqueles que acentuam a manutenção do status quo (estabilidade pessoal e tradição). Estes e os demais resultados precisam ser entendidos à luz do que tem sido pesquisado na literatura.

\section{DISCUSSÃO}

Pesquisas recentes têm demonstrado que as pessoas tendem a não demonstrar preconceito em relação a grupos minoritários (Gouveia et al., 2006). Esta tendência parece relacionar-se tanto a traços de 
personalidade - sobretudo, o que leva o indivíduo a agir em consonância com o que acredita ser desejável socialmente (Rattazzi\& Chiara, 2003) - quanto a valores humanos (Gouveia et al., 2006; Martínez et al., 2006; Vera \& Martínez, 2004). Buscou-se, nesta oportunidade, conhecer precisamente o papel dos valores para explicar as motivações para proceder sem preconceito contra gays e lésbicas. Implicitamente, admitiu-se o pressuposto de que valores específicos são responsáveis pela promoção ou inibição do preconceito (Gómez \& Huici, 2001).

Parece que o preconceito contra homossexuais relaciona-se com o desejo dos heterossexuais de manter as tradições relativas ao gênero, tradições que são percebidas como transgredidas pelos homossexuais (Lacerda et al., 2002; Vera \& Martínez, 1994; Whitley \& Egisdóttir, 2000). Os resultados anteriormente apresentados são congruentes com esta concepção. Evidências foram observadas quando valores normativos (por exemplo, religiosidade e obediência) se correlacionaram negativamente com a motivação interna para proceder sem preconceito. Assim, as pessoas guiadas por tais valores provavelmente procedem sem preconceito menos em razão de sua convicção interna, de suas crenças de que não devem se comportar preconceituosamente em relação aos homossexuais e, provavelmente, mais em razão de pressões sociais.

Em um estudo realizado por Vera e Martínez (1994) foi verificado que o tipo motivacional de valor universalismo se correlacionou negativamente com atitudes preconceituosas, isto é, pessoas que consideram como importantes os valores justiça social, igualdade, harmonia interior e sabedoria apresentam em menor medida tais atitudes. Resultado semelhante foi encontrado por Gouveia et al. (2006) quando tiveram em conta a subfunção valorativa suprapessoal, que se correlacionou com a motivação interna para proceder sem preconceito. Estes achados foram corroborados no presente artigo, o que indica que este tipo de motivação reflete valores que não se limitam à dicotomia pessoal versus social, sendo mais idealistas do que materialistas (Gouveia et al., 2008), potencialmente promovendo atitudes menos preconceituosas.

Martínez et al. (2006) procuram explicar o preconceito a partir de um modelo dual de valores, cujos resultados são, em geral, consistentes com os anteriormente apresentados. Este modelo sugere que existe uma relação dual entre os valores e as atitudes em relação aos exogrupos, em que um fator fomenta e o outro impede ou suprime o preconceito. Por um lado, os valores convencionais do individualismo, como aqueles da ética protestante (por exemplo, êxito, poder) fomentam o preconceito e, por outro lado, este é inibido por valores que acentuam o igualitarismo, o humanitarismo (por exemplo, igualdade e justiça social). Não obstante, um resultado aparentemente contraditório ocorreu na subfunção realização (Vasconcelos et al., 2004), cujo valor específico prestígio consistentemente se correlacionou de forma direta com a motivação externa para proceder sem preconceito. Cumpre lembrar que a pessoa que dá importância a este valor busca sua realização pessoal, mas por meio do reconhecimento dos demais. Neste sentido, parece coerente que evite parecer preconceituoso diante de outras pessoas, motivado por pressões sociais (Gouveia et al., 2006).

Um resultado que chama a atenção na presente pesquisa é a subfunção existência. Para lembrar, seus valores têm orientação mais materialista, focando a estabilidade pessoal acima de qualquer coisa (Gouveia et al., 2008). Esta subfunção parece ser a base da motivação externa para proceder sem preconceito em relação aos gays e, principalmente, às lésbicas. No caso do primeiro grupo minoritário, a estabilidade pessoal fez parte do modelo de regressão para explicar a motivação interna para proceder sem preconceito em relação aos gays. Isto sugere que indivíduos que se pautam fortemente por este princípio axiológico não são preconceituosos por uma questão de "consciência", mas por receio de parecer socialmente indesejável diante dos demais. Neste sentido, buscam sua estabilidade, evitando o confronto e buscando ajustar-se ao grupo.

Em resumo, corroborando estudos anteriores sobre a área (Gouveia et al., 2006; Martínez et al., 2006; Vasconcelos et al., 2004), os valores podem ser considerados como construto importante para explicar as motivações para agir sem preconceito - no presente caso, contra os homossexuais (gays e lésbicas) como grupos-alvo. Neste sentido, confia-se que os objetivos desta pesquisa tenham sido alcançados, oferecendo contribuições para os estudos na área do preconceito.

A propósito do que se acaba de comentar, parece evidente que a motivação interna contribui para inibir o comportamento preconceituoso, sendo esta motivação promovida a partir de princípios axiológicos que enfocam o igualitarismo (Martínez et al., 2006). Não obstante, muito há ainda que conhecer acerca desta temática. Por exemplo, é preciso enfocar o papel das subfunções suprapessoal e normativa, pois, enquanto a primeira é um correlato preponderante da motivação interna quando o grupo-alvo é formado por gays, a segunda se associa mais com a motivação externa para proceder 
sem preconceito em relação às lésbicas. Pode ser que esta diferenciação indique a recusa declarada do homossexualismo masculino, quando comparado com o feminino, sobretudo no contexto tradicional em que a pesquisa foi realizada. Estudos futuros poderão ajudar a esclarecer dúvidas e, provavelmente, auxiliarão em pesquisas de natureza mais qualitativa, explorando o sentido que as pessoas atribuem a proceder sem preconceito em relação a tais grupos.

\section{REFERÊNCIAS}

Allport, G. W. (1954). The nature of prejudice. Reading, MA: Addison-Wesley.

Boer, D. (2009). Music makes the people come together: Social functions of music listening for young people across cultures. Tese de Doutorado Não-Publicada, Departamento de Psicologia, Victoria University of Wellington, Wellington, NZ.

Costa, W. S. (2007). Homossexualidade e direito à identidade sexual: um estudo à luz dos direitos da personalidade. Novos Estudos Jurídicos, 12, 297-307.

Formiga, N. S., Omar, A. G., \& Vaamonde, J. D. (2009). Atitudes frente aos grupos minoritários em brasileiros: análise fatorial confirmatória e modelagem de equação estrutural. Revista de Psicologia, 12, 71-84.

Formiga, N., S., Vasconcelos, T. C., Joca, E. C., \& Saraiva, C. P. (2005). As atitudes frente aos grupos minoritários: um estudo em termos das formas sutis do preconceito. Barbarói, 22/23, 107-127.

Gómez, A., \& Huici, C. (2001). Valores y reducción del prejuicio. In M. Ros \& V. V. Gouveia (Orgs.), Psicología social de los valores humanos: Avances teóricos, metotologicos y aplicados. Madri: Biblioteca Nova.

Gouveia, V. V. (2003). A natureza motivacional dos valores humanos: Evidências acerca de uma nova tipologia. Estudos de Psicologia (Natal), 8, 431-443.

Gouveia, V. V., Milfont, T. L., Fischer, R., \& Santos, W. S. (2008). Teoria funcionalista dos valores humanos. In M. L. M. Teixeira (Org.), Valores humanos e gestão: novas perspectivas (pp. 47-80). São Paulo: SENAC.

Gouveia, V. V., Souza Filho, M. L., Araújo, A. G. T., Guerra, V.M., \& Souza, D. F. M de. (2006). Correlatos valorativos das motivações internas e externas para responder sem preconceito. Psicologia: Reflexão $e$ Crítica, 19, 422-432.

Guerra, V. M. (2008). Community, autonomy, and divinity: Studying morality across cultures. Tese de Doutorado Não-Publicada. Departamento de Psicologia, University of Kent, Canterbury, Kent, UK.

Inglehart, R. (1991). El cambio cultural en las sociedades industriales avanzadas. Madri: Siglo XXI.
Lacerda, M., Pereira, C., \& Camino, L. (2002). Um estudo sobre as formas de preconceito contra homossexuais na perspectiva das representações sociais. Psicologia: Reflexão e Crítica, 15, 165-178.

Lauer-Leite, I. (2009). Correlatos valorativos do significado do dinheiro para crianças. Tese de doutorado Não-Publicada, Programa de Pós-Graduação em Teoria e Pesquisa do Comportamento, Universidade Federal do Pará, Belém.

Lima, M. E. O., \& Vala, J. (2004). As novas formas de expressão do preconceito e do racismo. Estudos de Psicologia, 9, 401-411.

Martínez, M. C. M, Paterna, C., \& Gouveia, V. V. (2006). Relevancia del modelo dual de valores en relación con el prejuicio y la intención de contacto hacia exogrupos. Anales de Psicología, 22, 243-250.

Pereira, C. R., Torres, A. R. R., Pereira, A., \& Falcão, L. C. (2011). Preconceito contra homossexuais e representações sociais da homossexualidade em seminaristas católicos e evangélicos. Psicologia: Teoria e Pesquisa, 27(1), 73-82.

Pettigrew, T. F., \& Meertens, R. W. (1995). Subtle and blatant prejudice in Western Europe. European Journal of Social Psychology, 35, 57-75.

Plant, E. A., \& Devine, P. G. (1998). Internal and external motivation to respond without prejudice. Journal of Personality and Social Psychology, 75, 811-832.

Ramos, S., \& Carraca, S. (2006). A constituição da problemática da violência contra homossexuais: a articulação entre ativismo e academia na elaboração de políticas públicas. Revista Saúde Coletiva, 16, 185-205.

Rattazzi, A. M. M., \& Chiara, V. (2003). Social desirability of subtle and blatant prejudice scale. Psychological Reports, 92, 241-250.

Rokeach, M. (1973). The nature of human values. New York: Free Press.

Santos, W. (2008). Explicando comportamentos socialmente desviantes: uma análise do compromisso convencional e afiliação social. Tese de doutorado nãopublicada, Programa de Pós Graduação em Psicologia Social, Universidade Federal da Paraíba, João Pessoa.

Schwartz, S. H. (1994). Are there universal aspects in the structure and contents of human values? Journal of Social Issues, 50, 19-45.

Tamayo, A., Lima, A., Marques, J., \& Martins, L. (2001). Prioridades axiológicas e uso de preservativo. Psicologia: Reflexão e Crítica, 14, 167-175.

Toro-Alfonso, J., \& Varas-Díaz, N. (2004). Los otros: Prejuicio y distancia social hacia hombres gays $\mathrm{y}$ lesbianas en una muestra de estudiantes de nivel universitario. International Journal of Clinical Psychology, 4, 537- 551.

Torrão Filho, A. (2005). Uma questão de gênero: Onde o masculino e o feminino se cruzam. Cadernos Pagu, 24, 127-152. 
Vasconcelos, T. C., Gouveia, V. V., Souza Filho, M. L., Sousa, D. M. F., \& Jesus, G. R. (2004). Preconceito e intenção em manter contato social: evidências acerca dos valores humanos. Psico-USF, 9, 147-154.

Vera, J. J., \& Martínez, M. del C. (1994). Preferencias de valores en relación con los prejuicios hacia exogrupos. Anales de Psicologia, 10, 20-40.
Whitley, B. E. Jr., \& Egisdóttir, E. (2000). The gender belief system, authoritarianism, social dominance orientation, and heterosexuals' attitudes toward lesbians and gay men. Sex Roles, 42, 947-967.

Recebido em 30/04/2010 Aceito em 15/06/2012

Endereço para correspondência:

Valdiney Veloso Gouveia. Universidade Federal da Paraíba, CCHLA, Departamento de Psicologia, CEP: 58.051-900, João Pessoa-PB, Brasil. E-mail: vvgouveia@gmail.com. 